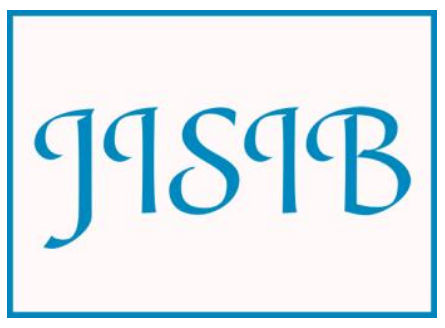

Available for free online at https://ojs.hh.se/

Journal of Intelligence Studies in Business 3 (2012) 29-40

\title{
Using the SSAV model to evaluate Business Intelligence Software
}

\author{
Yasmina Amara, Klaus Solberg Søilen* and Dirk Vriens† \\ *(Corresponding author), Halmstad University, Sweden \\ klasol@hh.se \\ $†$ Nijmegen School of Management, Netherlands \\ d.vriens@fm.ru.nl
}

Revised version accepted December 202012

\begin{abstract}
Choosing the right Business Intelligence (BI) software is critical to increasing productivity and effectiveness in organizations today. At the same time it is a very elaborating and complex process to choose the right software due to the fact that a large number of BI products exist on the market, which are quite different and updated frequently. The objective of this study is to develop and test a model for the evaluation of BI Software. The findings of the study revealed that it is difficult to declare what is the most competitive BI software as what is good for one user might not be good for another depending on their different business needs. Having said that the study initiated a new classification of BI Software vendors depending on the degree to which they comply with the functions in the Competitive Intelligence (CI) cycle. The software tested was divided into five categories: Fully complete, Complete, Semi Complete, Incomplete and Insubstantial. We conclude that the SSAV (Solberg Søilen, Amara, Vriens) Model Together with some proposed non technological variables and a classification developed can be used as a user's selection tool for deciding which BI Software to purchase.
\end{abstract}

KEYWORDS: Business Intelligence, Software evaluation, Competitive Intelligence, SSAV model

\section{Introduction}

With the emergent volume of data handled by companies in our fast changing business environment, staying competitive means constantly analyzing the existing market for relevant changes. This puts a burden on business owners, continuously to find and interpret information that is imperative for their survival. According to Gartner Group (2007) "The amount of data collected by an organization doubles every year.
Knowledge workers analyze only $5 \%$ of this data. Knowledge workers spend $60 \%$ of their time searching for important relationships in the data, $20 \%$ analyzing the discovered relationships, and only $10 \%$ on doing something with the analysis (i.e., making decisions, implementing strategies and plans, etc.). Information overload reduces decisionmaking capability by $50 \% "$. There is an increasing demand for software that can assist in this process, what is broadly known as Business Intelligence 
(BI) software (for a list, see Solberg Søilen, K. 2005).

\section{Problem formulation}

The purpose of this research was to generate a new model with a new set of criterion for evaluating BI software. The idea was to propose an assortment of evaluation variables for each function of the CI cycle. So far the BI term has been used by a too large variety of software solutions. Moreover, the research aimed at testing the model upon a chosen sample of BI software vendors to determine the most complete BI Software. The aim was also to determine the software's most important values, which ought to be considered by companies when deploying BI applications. The new BI Software evaluation criteria and vendors categories aim to differentiate various vendors in the market and hence initiating a more informed user selection discussion.

The research will attempt to answer the following questions:

- What discussed variables/criteria are selected for evaluating Business Intelligence BI software?

- How are these BI software variables measured?

- According to the criterion selected what are the most competitive BI Software available among the few that have been selected?

- What credible categorization can be used to classify BI Software vendors?

- What is the potential for the proposed variables/criteria and vendor's categories?

\subsection{A short background to the problem}

Business survival today is based on companies' abilities to analyze their rivals' moves, and to anticipate market developments rather than simply react to them (Millre, S. 2001). CI enables senior managers in companies of all sizes to make informed decisions about everything from marketing, $\mathrm{R} \& \mathrm{D}$, and investing tactics to long-term business strategies. Moreover, CI is considered a value-added concept that outperforms the top of business development, market research and strategic planning (Arik, J. 2005).

Authors mostly refer to two reasons for obtaining a competitive intelligence capability. Firstly, CI contributes to the overall organizational goals such as improving its competitiveness or maintaining the viability of the organization. In addition it contributes to the organizational activities needed to reach the overall goal like decision-making or strategy formulation (Vriens, D. 2003). Hence as claimed by Jan P. Herring (1993) the roles of $\mathrm{CI}$ efforts fall into the following categories:

- Strategic decisions and actions (tactics)

- Early-warning topics that prevent surprises to the organization relating to product launches, new emerging, or changing market and new technologies or business methods

- Knowledge of, learning from and assessments of key players and competitors, and

- Intelligence assessments for planning and strategy development.

Therefore, with CI capabilities a business can predict the action of their competitors \& key players, remain competitive in the market and reach its goals through better decisions and more focused strategy planning.

\subsection{Business Intelligence (BI) software}

More and more intelligence tasks today are automated, by the use of Business Intelligence. Effective competitive intelligence results not from luck, but from the same careful planning, discipline, and systematic process that scientists employ. "However, the companies with the highest success rates at winning new business have found that competitive intelligence is not a magical art; it is a science whose ethical practice readily impacts a company's top and bottom lines" (O'Quinn, O. 2001). According to Vriens (2003) in order for the intelligence cycle to be carried out properly, an organization should implement a balanced mix and an intelligence infrastructure that consists of following three parts:

- A technological part, comprising the ICT applications and ICT infrastructure that can be used to support the intelligence cycle phases

- A structural part, referring to the definition and allocation of CI tasks and responsibilities (e. g., should CI activities be centralized or decentralized), and

- A human resources part, which has to do with selecting, training and motivating personnel that should perform the intelligence activities.

Thus, although technology matters for building effective CI it should be combined with good planning for the allocation of the CI tasks, making sure CI activities are carried out by professionals and get others involved. Human resource departments should plan the selection of CI staff cautiously to ensure a superior CI performance. 
All along different Information \& Communication Technologies (ICT) tools are used for supporting the different activities in the competitive intelligence cycle. ICT for CI (or Competitive Intelligence Systems, CIS) is best seen as a collection of electronic tools (Vriens, D. 2003) that support strategic decision-making, that are dispersed over different management levels; and that supports structured and unstructured intelligence activities.

According to Vriens three types of ICT tools can support or sometimes even replace the CI activities: the internet as a tool for direction or collection activities, general applications to be used in CI activities (groupware or intranets etc) and Business Intelligence software. This paper is concerned with the latter.

\section{Method}

Empirical research was carried out to test the developed model. A selected sample of BI Software vendors and their products was tested against the set of evaluation criteria originated from the conceptual work. Initially a custom-made cover letter requesting free access to the sample vendor's products for measuring purposes was sent out. The vendor's sample which has been integrated in the evaluation is a non-probability purposeful quota sample that includes 11 BI Software products: Business Objects, Microstartegy, Microsoft, Information Builders, Panorama, QlickView, Spotfire, Cognos, SAS, Astragy and Digimind. Observations and experiments were conducted using mostly the free software accesses obtained from the software trial demonstrations already available and the vendors' presentations \& white papers to collect data regarding the capabilities. The evaluation model developed with its variables and proposed measuring scale (Likert Scale) were documented and mapped as a checklist and used to evaluate the BI software samples and demeanor quantitative analysis of numerical data obtained from the Likert scale scores enabling the comparative investigation of the BI vendors who are participants in the study.

The research will attempt to answer the following questions:

1) What discussed variables/criteria are selected for evaluating Business Intelligence BI software?

2) How are these BI software variables measured?

3) According to the criterion selected what are the most competitive BI Software available among those few that have been selected?

4) What credible categorization can be used to classify BI Software vendors?
5) What is the potential that the proposed variables/criteria and vendor's categories can be used as BI Software users' selection foundation?

For business intelligence systems to be successful, there is need to create an appropriate infrastructure to capture and create data, information, and knowledge, and store them, improve them, clarify them, analyze them and disseminate them to decision makers so that there can be an overall understanding of a company's operations for actionable results (Thierauf, R. 2001).

Thus for ensuring effective business intelligence platform, five essential steps are needed: Understanding the problem, collecting the data, analyzing the data, sharing the results, and acting on the information which represents the phases of the CI cycle all of which are supported with different technologies (capabilities) whether data warehousing, business analytics, Analytical models (user's interfacing) Business Performance Management (BPM), user's interfacing as explained by Ericsson (2004): 
Figure 1: BI SOFTWARE CAPABILITIES

(Ericsson, 2004)

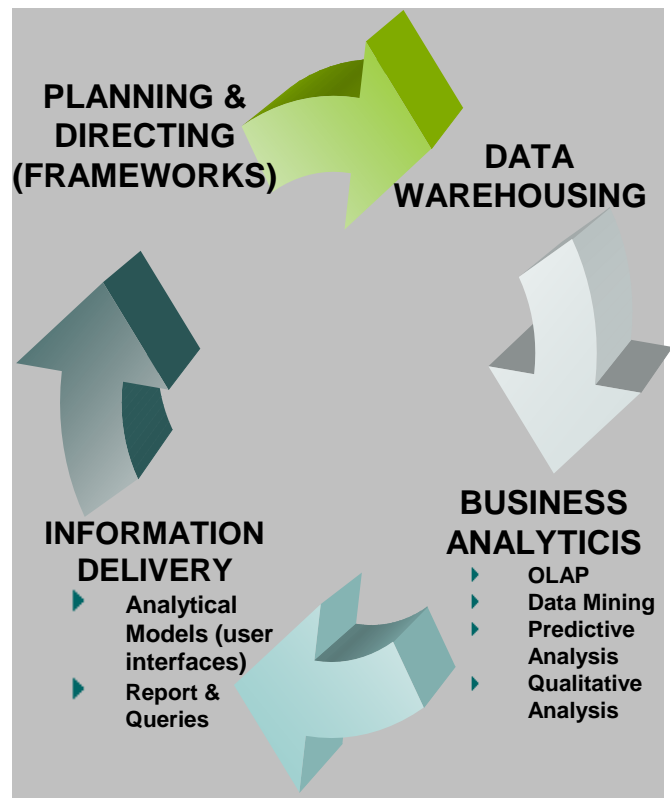

The priorities of the business are understood here by mapping the existing data flows and structures and understanding the needs of the decision makers (Ericsson, 2004). This BI function basically supports the planning phase in CI cycle.

\section{1 Software Evaluation}

"Business organizations are still struggling to improve the quality of Information Systems (IS) after many research efforts and years of accumulated experience in delivering them" (Duggan, E. 2006). Building an information system, whether it is a customized product for proprietary use or generalized commercial package, means providing sophisticated high-quality software, with the requisite features that are useable by clients, delivered at the budgeted cost, and produced on time. However, these goals are not frequently met; "Hence, the recurring theme of the past several years has been that the Information System community has failed to exploit IT innovations and advances to consistently produce high-quality business applications" (Brynjolfsson, 1993; Gibbs, 1994). The evaluation of software and its business value are recently the subject of many academic and business discussions. Since Investments in IT are growing extensively, and business managers worry about the fact that the benefits of IT investments might not be as high as expected (Van Grembergen, 2001). The business value of a software product results from its quality as perceived by both acquirers and end users. Therefore, quality is increasingly seen as a critical attribute of software, since its absence results in financial loss as well as dissatisfied users, and may even endanger lives (Duggan, E. 2006). Thus users' perception of software quality is the base of evaluating software.

Palvia (2001) interpreted information system quality as discernible features and characteristics of a system that contribute to the delivery of expected benefits and the satisfaction of perceived needs. Other scholars, such as Ericsson and McFadden (1993), Grady (1993), Hanna (1995), Hough (1993), Lyytinen (1988), Markus and Keil (1994), Newman and Robey (1992), have further explicated IS quality requisites that include:

- Timely delivery and relevance beyond deployment

- Overall system and business benefits that outstrip life-cycle costs

- The provision of required functionality and features

- Ease of access and use of delivered features

- The reliability of features and high probability of correct and consistent response

- Acceptable response times

- Maintainability which means easily identifiable sources of defects that is correctable with normal effort

- Scalability to incorporate unforeseen functionality and accommodate growth in user base, and

- Usage of the system.

Besides Quality, Bass (1998) uses the following attributes to evaluate software:

- Performance: The responsiveness of the software

- Reliability: The ability of the software to keep operating

- Availability: The proportion of time the system is up and running

- Security: The measure of the software ability to resist unauthorized attempts at usage and denial of service while providing the service to the user

- Portability: Is the ability to make changes to software quickly and cost effectively

- Functionality: The ability of the software to do the work for which was intended

- Variability: How well the software can be expanded or modified

- Conceptual Integrity: The underlying theme or vision that unifies the design of the software at all levels, and

- Usability: The user's ability to utilize software effectively. 
Furthermore, Fenton \& Pfleeger (1997) introduced a quality model which evaluates software based on the following three dimensions.

- The People dimension: This dimension includes the competent IS specialists along with their skills and experience necessary to manage both the technical and behavioural elements of the software. Whereas delivery is central to ensuring high-quality IS products (Perry et al., 1994).

Additionally, it is said that the user-centred perception of the software delivery increase the opportunity of producing higher quality systems (Duggan, E. 2006).

- The Process dimension: This dimension prescribes the timing of each deliverable, procedures and practices to be followed, tools and techniques that are supported, and identifies roles, role players, and their responsibilities (Riemenschneider et al., 2002).

Its target is process consistency and repeatability as IS projects advance through the systems life cycle (Duggan, E. 2006).

- The Product dimension: The product quality is concerned with inherent properties of the delivered system that users and maintenance personnel experience (Duggan, E. 2006).

The noticeable growth in the BI Software market is leaving companies of different spheres in bewildering status by having to decide amongst diverse BI software vendors that want to assist them to achieve their business objectives.

According to CBR staff writer (2007) "the scope for differentiation between BI vendors has shifted higher up the stack, towards issues such as predictive analytics and real-time BI. It has also moved lower down the stack, towards more pervasive $\mathrm{BI}$ and client $\mathrm{BI}$ applications. Other differentiation strategies may focus on strategic issues such as ease of deployment, on-demand offerings, industry-specific packages, enterprise application integration or go-to-market approaches". For this reason, choosing the right BI software is critical to increase productivity and effectiveness in the organization. Nevertheless it is a very elaborating and complex process due to the fact that numerous BI software packages exist on the market most of which are updated very rapidly.

Most importantly the selection process involves various criteria and variables against which BI software are compared and evaluated which on the whole are not apparent and generally vague (Turban et al., 2007). Besides, most of the evaluations done are not able to combine both the testing of the BI effectiveness as a tool and its support of the phases in the Competitive Intelligence CI Cycle. So far only Gartner, Forrester and Fuld \& Company are established for performing evaluations of BI software. The attributes that are used here to evaluate software can't be used directly for evaluating BI Software. Hence the need to find specific attribute to evaluate BI Software quality.

\subsection{Gartner}

Gartner Inc. is accredited for having introduced the term "business intelligence". Gartner initiated the Magic Quadrant for Business Intelligence Platforms evaluation which states that users should evaluate vendors in all four quadrants, including the Niche Players, Visionaries, Leaders and Challengers. According to Gartner research 2005 the vendors are placed in one of four positions (leaders, challengers, visionaries and niche players) in a "magic quadrant." As follows:

- Leaders: have strong market position, solid customer support, and an extensive pool of skilled developers. Their products have generic functionality. Also, there is limited or no access to key personnel, and there is little room to negotiate prices.

- Challengers: are characterized by their stability, solid customer support, reliable technology, and functional completeness. Their products' architecture may be outdated, they have a limited pool of skills, and they may compete with potential application partners.

- Visionaries: have cutting-edge functionality in their offerings and have the potential for aggressive discounting. On the flip side, they are potentially unstable, offer limited support, and have an extremely meagre skills pool.

- Niche players: typically have critical and unique functionality - but they have a limited ability to compete in the market and enhance their product. Of course, not all of these characteristics apply to each and every one of the vendors, but they serve as a framework to categorize them for comparison purposes.

Vendors were included in the Magic Quadrant if they met the following requirements:

- They deliver at least eight of the (12) BI platform capabilities divided into three functionality categories integration, information delivery and analysis. 
- They have a reasonable market presence, which we define as greater than $\$ 20$ million in annual revenue from BI platform software.

- They demonstrate that their solutions are used and supported across the enterprise, and go beyond departmental deployments. (Gartner 2007).

Later on the vendors who can be added to Gartner's magic quadrant are evaluated based on two evaluation criterions. The first is based on vendor's ability and success in making their vision a market reality and the second on their understanding of how market forces can be exploited to create value for customers and opportunity for themselves.

To conclude, Gartner's evaluates BI Software from the pure business perspective. It assesses BI software ability to achieve its business goals and vision. Although it looks at BI software functions to determine the intrusion condition of any BI software in the Gartner's evaluation, it doesn't measure the BI functions effectiveness nor the software support of the CI cycle phases.

\subsection{Forrester Wave BI}

Forrester Wave BI Software evaluation includes a detailed in depth evaluations criteria based on three level buckets: Offering, Strategy, and Market Presence (Keith, G. 2006). Forrester wave evaluates BI vendors who met the following criteria:

- A vendor with annual estimated BI revenue in excess of $\$ 100$ million

- A vendor with or more products specifically targeted at the BI reporting and analysis market, and

- A market-leading pure-play BI vendor, RDBMS, or enterprise application vendor with a native analytic or enterprise reporting product/component, or a supporting reporting engine and repository.

Forrester found through users interviews that most users are unsatisfied with the way they currently receive analytic information. Thirty percent of those surveyed thought their analytic software has significant gaps in usability. Twenty-two percent cited lack of detail as an issue. Forrester assesses the BI vendors on their functions effectiveness and usability but in a very general manner without going into any depth of each BI capability. Moreover, it didn't evaluate the level of support BI software functions provide to the CI cycle phases.

\subsection{Fuld \& Company CI Software evaluation}

Fuld \& Company compare CI users' reactions of CI software to those of animals with certain traits in order to motivate hundreds of users to respond and complete a survey that is aimed to convey both the characteristics of the technology and their responses to that technology. The animals they chose were as follows:

- Slug because of its lack of speed and responsiveness

- Gerbil a fast animal but one that seems to go in circles, quickly spinning its wheels, but going nowhere

- Bee for its speed, smarts, and sense of the bigger picture

- Parrot that would spit back the information, adding little, and

- Labrador a dog who would go and retrieve what you need when you need it.

"The largest single segment of respondents, $42 \%$, compared their competitive intelligence CI technology to a bee- an insect that "creates a useful pattern or swarm of information and helps me connect the dots." Nearly one-third (29\%) saw their solution more like a Labrador retriever, "good at fetching and retrieving."

A vocal minority of nearly $30 \%$ of respondents gave the software low grades, comparing it to a parrot (11\% - "just spits back what you sent to it; no added value"), a slug (12\% - "just takes up space and never seems to go anywhere"), or a gerbil (6\% - "lots of action, spins its wheels and offers no substance whatsoever - and definitely consumes my time") (Fuld \& Company, 1999).

Fuld \& Company evaluates the software packages with regard to the five steps of the Intelligence Cycle in relation to how much we can reasonably expect the technology to support each step of the CI Cycle. They first had to distinguish between packages that promoted themselves as Business Intelligence tools. "Business Intelligence software", as the industry labels many of its products, typically deals with data warehouses and quantitative analysis, almost exclusively of a company's internal data (e.g. CRM, Customer Relationship Management data) (Fuld \& Company intelligence report, 2006-2007).

Fuld (2002, page 12-13) state that the fulfilment of the following functions acts as criteria in judging $\mathrm{CI}$ applications in the direction phase:

- Providing a framework to input Key Intelligence Topics and Key Intelligence Questions, and

- Receiving CI requests managing a CI work process and project flow that allows 
collaboration among members of the CI team as well as with the rest of the company.

For the data collection phase the criteria includes the following:

- The ability to capture qualitative, 'soft' information from employees throughout the company, either through internal message boards, e-mail, or another easily accessible medium by which primary information can be inputted and retrieved

- The capacity to target and retrieve qualitative information (such as consumer feedback) from message boards, news groups, and other external forums, and

- An area in the software and user interface for inputting interviews, field reports, and other first-hand accounts.

The criteria for the analysis phase include:

- The ability to sort information by user-defined rules

- Data visualization interface(s) to sort and view collected information

- Multiple viewing models, such as SWOT (Strength Weaknesses Opportunities Threats) and Porter's Five Forces model

- Display of information in chronological order

- Extraction of relationships between people, places, dates, events, and other potential correlations

- Text-mining technology to locate and extract user-defined variables, and

- The ability to relate analyses to quantitative data.

For the reporting and informing phase:

- Both standardized and customizable report templates

- The ability to link and export reports to Microsoft Office formats, CorelDraw, PDF, multimedia formats, other databases, and/or other reporting systems, and

- The capability to deliver reports via hard copy, the corporate intranet, e-mail, and/or wireless sources.

Fuld's evaluation criteria evaluated software packages with regard to the backup it provides for the four CI Cycle phases. The software packages that have participated in the Fuld's evaluation were the one not dealing with BI functions from: Frameworks, Data Warehousing, Business analytics and User's interface but rather those with more simple functions assigned for planning, data collection, and analysis and information delivery methods.

Fuld's criteria didn't measure the effectiveness $\&$ efficiency of the software as a tool. Hence, this study used and set off further from Fuld's Model criteria by applying the developed Model on Software packages escorts BI functions.

\section{Results and Analysis}

The SSAV BI Software evaluation Model was developed and tested on a sample of BI Software discussed earlier by analyzing their various capabilities (Functions). Its aim is to evaluate BI Software effectiveness \& efficiency as a tool in addition to assess how each BI function supports a particular CI activity in the cycle. Moreover, the variables used for evaluating BI Software can be divided into the following three classes:

- PROCESS VARIABLES I: They include variables for evaluating the effectiveness $\&$ efficiency (quality) of BI Software functions (Capabilities).

- PRODUCT VARIABLES: They include variables for evaluating the effectiveness $\&$ efficiency (quality) of artifacts, deliverables or documents that result from BI Software function, and

- $\quad$ PROCESS VARIABLES II: They include variables for evaluating how a BI function supports a particular CI cycle activity.

Consequently, the variables used in the evaluation criterion were divided into four parts as illustrated.

A five point Likert scale was used to evaluate the BI Software functions against the developed evaluation criteria by selecting a number from highest to lowest (0-4) for each specified trait/variable. The numbers are arranged horizontally and are added up to arrive at an overall score as follows:

$$
\begin{aligned}
& 4=\text { EXCELLENT, } \\
& 3=\text { GOOD, } \\
& 2=\text { SATISFACTORY }, \\
& 1=\text { POOR, } \\
& 0=(N / A)
\end{aligned}
$$

Seeing that, selecting the right BI software is critical to improve the productivity and effectiveness of organizations huge burdens are put into developing a suitable methodology that can be used for selecting BI software that will best suit the users' needs.

In this paper the focus is to develop a new technological Model for evaluating BI software 
effectiveness \& efficiency as a tool besides assessing the extent in which they support the four phases of the CI cycle. Consequently, these technological variables can be used as a starting point when selecting a BI tool.

Although, the technological variables can aid users in narrowing down their BI vendors alternatives, they are not enough. Further, investigation should be conducted to extract some non technological variables which could be critical to enhance users end decision regarding which BI tool to pursue.

Three additional non technological variable groupings can be used as a BI evaluation criterion and hence as a selection tool as demonstrated below.

- Human \& Structural Variables: It includes variables relating to the effectiveness of the development teams and the allocation of CI tasks and responsibilities among them. Moreover it has to do with the human competencies that should be available when selecting, training and motivating personnel that should perform the intelligence activities. The proposed human \& structural variables are illustrated in the table (4) below:

- Users Variables: They include variables concerning the In-House staff using the software. As shown in table (5) below.

- Vendors Variables: Usually the final choice regarding the BI tool selection is often based on the ability of the chosen vendor to support the company's current and future projects in terms of stability, resources, and experience.
Consequently, to aid users in their BI tool selection it is recommended to evaluate the software upon the technological and non technological variables mentioned in this chapter using the Likert scale. However, in this study only the technological variables are used in the SSAV Model to test some BI vendors' software for two reasons, time constraints and the difficulty to assess the non technological variables using the projected methodology. Using BI Vendors free trials, demos, presentations and white papers collected, performance assessment along with comparative analysis were conducted for each vendor software participating in testing the SSAV Model; resulting in a pertinent score on the Likert scale for each variable in the different BI Functions \& CI phases of the Model for each vendor. In addition to an overall score for each BI function, support of CI Cycle phase and the total phase score were calculated correspondingly for each BI participant.

\subsection{The most competitive BI Software}

Saying that a particular BI Software vendor is the most competitive is not possible. It is possible to say that a certain BI vendor concentrates and stands out in one phase or more in the CI cycle while disregarding the rest. Moreover, a software vendor can do better in a certain BI function compared to the others functions.

So, it is of great importance for users to determine what intelligence cycle feature or BI software function is essential to work properly. And decide which software to purchase. On the other hand it is important to be able to spot the complete (standard) BI vendors which offer the four CI cycle phases in one package and identify those who have the highest overall score in the CI phases together. Below are the findings resulted from analyzing the Likert scale scores for the limited number of BI Software vendors who participated in this study.

\subsection{The top data collection vendors}

According to the scale below Information Builders is the best BI vendor when it comes to data collection followed by Cognos and Business Objects. Alternatively TIBCO Spotfire is the least good. 
TABLE 1: BI SOFTWARE RANKING IN DATA COLLECTION

\begin{tabular}{|c|l|}
\hline RANKING & \multicolumn{1}{|c|}{ BI SOFTWARE VENDOR } \\
\hline 1. & INFORMATION BUILDERS \\
\hline 2. & COGNOS \\
\hline 3. & BUSINESS OBJECTS \\
\hline 4. & SAS \\
\hline 5. & MICROSOFT \\
\hline 6. & PANORAMA \\
\hline 7. & MICROSTRATEGY \\
\hline 8. & QLICKVIEW \\
\hline 9. & TIBCO SPOTFIRE \\
\hline 10. & ASTRAGY \\
\hline 11. & DIGIMIND \\
\hline
\end{tabular}

Source: Evaluation Results

As for the two CI software vendors Digimind and Astragy they come at last since they don't provide

\section{TABLE 2: BI SOFTWARE RANKING IN} ANALYSIS

\begin{tabular}{|c|l|}
\hline RANKING & \multicolumn{1}{|c|}{ BI SOFTWARE VENDOR } \\
\hline 1. & SAS \\
\hline 2. & MICROSOFT \\
\hline 3. & BUSINESS OBJECTS \\
\hline 4. & MICROSTRATEGY \\
\hline 5. & COGNOS \\
\hline 6. & TIBCO SPOTFIRE \\
\hline 7. & PANORAMA \\
\hline 8. & ASTRAGY \\
\hline 9. & DIGIMIND \\
\hline 10. & INFORMATION BUILDERS \\
\hline 11. & QLICKVIEW \\
\hline
\end{tabular}

Source: Evaluation Results

any BI functions which here contribute to the data collection overall score. Both vendors score high in supporting the CI data collection variable but using different means and functions.

\subsection{The top vendors in analysis}

From the next figure we see that SAS is the best in analysis followed by Microsoft and Business Objects. And the vendor who is less good in analysis is QlickView. While the rest vendors analytical capabilities are somehow below average. Again although Digimind \& Astragy provide good analysis their score are low on the scale since they don't provide any BI business analytics from OLAP, data mining, predictive or qualitative analysis. When it comes to the ability of Dissemination the list is as follows:
TABLE 3: BI SOFTWARE RANKING IN DISSEMINATION

\begin{tabular}{|c|l|}
\hline RANKING & \multicolumn{1}{|c|}{ BI SOFTWARE VENDOR } \\
\hline 1. & BUSINESS OBJECTS \\
\hline 2. & COGNOS \\
\hline 3. & PANORAMA \\
\hline 4. & INFORMATION BUILDERS \\
\hline 5. & MICROSTRATEGY \\
\hline 6. & TIBCO SPOTFIRE \\
\hline 7. & SAS \\
\hline 8. & MICROSOFT \\
\hline 9. & QLICKVIEW \\
\hline 10. & DIGIMIND \\
\hline 11. & ASTRAGY \\
\hline
\end{tabular}

Source: Evaluation Results

The top dissemination vendors are Business Objects, providing the best information delivery, followed by Cognos and Panorama. Microstartegy is at the bottom of the list. As for Astragy and Digimind they have low scores for the same reason mentioned above though their score for supporting the CI dissemination phase is almost the same as for other BI vendors.

\subsection{The top vendors in planning \& directing}

Astragy is the only vendor who supports this phase of the CI cycle as its consultants helps and advises users with the organization of their intelligence system. No list is therefore added here.

The most complete (standard) vendors are Business Objects, with the highest overall score making it the most complete vendor followed by Cognos, Microsoft and Information Builders. QlickView has the lowest overall score.

If the total score was calculated by adding up only the CI phases supporting variables without the BI functions variables Digimind would have scored highest followed by Business Objects. From the empirical findings and their analysis a new categorization for BI software can be generated. This categorization segregate BI Software into five categories depending on the level of support it provides for the CI cycle phases as follows.

- Fully complete: BI Software in this category excels in the four phases of the CI Cycle including: planning, data collection, analysis and dissemination.

- Complete: Since the planning \& directing phase is seldom supported by any BI software, they can be considered complete but not fully complete if it performed very well in the other three phase of the CI cycle: Data collection, analysis and dissemination.

- Semi complete: In the case the BI Software excels in two CI phases out of four it is 
considered to join this category For example: Data collection \& Analysis, Data collection \& Dissemination or Analysis \& dissemination.

- Incomplete: When the BI Software stands out in only one phase of the CI cycle it is positioned as incomplete. For example: merely data collection, solely analysis or just dissemination.

- Insubstantial: If the BI Software perform well in any of the CI cycle phases is it included in this category.

In order to consider a BI software excelling in a phase it ought to have an overall score of (2.5) or more in that particular phase on the Likert scale. Consequently, the sample BI software evaluated can be classified using this categorization, as shown in the following table:

\section{TABLE 4: BI SOFTWARE CLASSIFICATION}

\begin{tabular}{|c|c|c|}
\hline $\begin{array}{c}\text { BI } \\
\text { SOFTWARE }\end{array}$ & CATEGORY & PHASES IT EXCELS IN \\
\hline $\begin{array}{l}\text { Information } \\
\text { Builders }\end{array}$ & Semi Complete & $\begin{array}{l}\text { Data Collection } \quad \& \\
\text { Dissemination }\end{array}$ \\
\hline Microstrategy & Incomplete & Dissemination \\
\hline Microsoft & Semi Complete & Data Collection \& Analysis \\
\hline $\begin{array}{l}\text { Business } \\
\text { Objects }\end{array}$ & Complete & $\begin{array}{l}\text { Data Collection, analysis \& } \\
\text { Dissemination }\end{array}$ \\
\hline Panorama & Semi Complete & $\begin{array}{l}\text { Data Collection \& } \\
\text { Dissemination }\end{array}$ \\
\hline Cognos & Semi Complete & $\begin{array}{l}\text { Data Collection \& } \\
\text { Dissemination }\end{array}$ \\
\hline Spotfire & Incomplete & Dissemination \\
\hline QlickView & Insubstantial: & None \\
\hline SAS & Semi Complete & Data Collection \& Analysis \\
\hline
\end{tabular}

Source: Evaluation Results

The proposed categorization can be used as a foundation when selecting BI Software by enabling users to clearly see what CI phases are critical for serving their business needs.

\section{Conclusions}

The purpose of this paper was to develop a model (The SSAV Model) with a scale and test it on a small sample of BI vendors. Moreover the aim was to decide upon which BI Software is the most competitive, classify them using a credible categorization and examine the models' and the categorizations' potential to be user's selection foundation.

By reviewing the theoretical framework comprehensively, the SSAV model with its evaluation criteria for assessing BI Software using a five point (0-4) Likert scale is developed. It consists of technological variables covering the BI functions and CI cycle phases which is capable of evaluating the BI tool effectiveness \& efficiency as well as assessing its level of support for the CI cycle phases. Thus, being able to build up a model that benefits and add from previous evaluations' models as Gartner, Fulds and Forrester Wave.

The assertion that a particular BI Software vendor is the most competitive is difficult. A Business Intelligence vendor might excel in one phase or more in the CI cycle and/or stand out in a certain BI function while disregarding the rest. Accordingly, it is of great importance to determine what intelligence cycle feature or BI software function is crucial to work properly for them users when pursuing BI software.

As of the analysis of the empirical findings for our limited number of BI software participants we found that Information Builders is number one in data collection, SAS is the best in analysis and business objects is the leader in dissemination. The most complete BI tool are Cognos and Astragy, the only vendor in our sample who supports the planning \& directing phase of the CI Cycle. Additionally, Information Builders are the top in providing data warehouses and data integration; Business Objects excels in metadata reports, qualitative analysis, user interfaces and reports.

The best OLAP is from Microstrategy and Data Mining \& predictive analysis from SAS. Whereas Cognos stands out in the user interfaces \& in reporting.

It is crucial to point out that Astragy \& Digimind BI Software don't include any kind of frameworks, Data warehousing, Business Analytics or user interfaces capabilities or any other BI Software functions being evaluated in the SSAV Model. Their more ordinary common functions for supporting the CI cycle phases results in a low score on the overall CI cycle phase score, even though they could be achieving an outstanding performance in that particular phase. Hence, further adjustment ought to be started in order to develop a model that will be able to give these kinds of BI Software a more reliable evaluation. Generally speaking the planning \& direction phase of the CI Cycle is not commonly available in any BI Software being evaluated. Therefore more attention should be given to the development of frameworks that support this phase since it is fundamental for determining the strategic information requirement and it is considered the base for the other phases in the CI Cycle.

Nevertheless, the analysis of the empirical shows that on average BI vendors perform good in the dissemination and data collection phases but still most of them lack the analytics capabilities where more emphasize should be placed.

Lastly, BI Software vendors nowadays can be classified into five categories: Fully Complete, Complete, Semi Complete, Incomplete and 
Insubstantial depending on the level of support it provides for the CI cycle phases. Hence, it can be a further help for users' selection of the BI Software vendor that best meets it business needs by helping users select from these five categories the BI Software that will aid them in achieving their long $\&$ short term objectives.

Business Objects is the only complete BI vendor among the vendors being evaluated. Information Builders, Microsoft, Panorama, Cognos and SAS belong to the semi complete category. Whilst, Microstartegy and Spotfire are considered Incomplete and QlickView Insubstantial.

Accordingly, the technological variables of the SSAV Model, the proposed non technological variables and the categorization developed can together be used as users' BI Software selection tool.

\section{Suggestions for further study}

During the theoretical and empirical study, many questions, which deserve further investigation, have come up. These questions can be answered through some future studies. So the followings future studies can be suggested subsequently.

One of the findings of this study was that the SSAV Model of technological criterion in conjunction with the proposed non-technological variables consisting of Human, users and vendors factors are to be used to evaluate BI Software. Consequently, the first suggestion for future studies is to test these non technological variables on the BI Software.

This couldn't been done during this study due to the time limitations as it was difficult to observe development teams in their natural working environments nor conduct personal interviews with end users and BI vendors.

Additionally, free software accesses, free trial demonstrations, vendor presentations and white papers were used to compare BI Software and grant each a score on the Likert scale depending on the variable being evaluated which good to some extent. But, in order to get more accurate measuring results an alternative way could be implemented which were constricted along with the time factors.

The alternative measuring method can include using the same data source (Data set) for all the participant BI vendors and thus tracking what occurs to this data source throughout the whole CI cycle phases for each vendor separately and can be considered as a further suggestion for advanced studies.

Besides, again due to the time constraints and not being able to get free trials from all the credible
BI vendors the SSAV Model was tested only on 11 $\mathrm{BI}$ vendor. So, in order to make a more comprehensive reliable evaluation it is vital to include the rest in another study. At least it can include: Proclarity, Teradata, Pilot, prelytis, Epicor, Codec, SAP and ComArch.

Finally, the SSAV Model couldn't be totally applied on Astragy and Digimind BI Software since they don't contain the usual BI functions like Frameworks, data warehousing, business analytics and user interface but rather other functions that support the CI Cycle phases. Accordingly, Building a new version of this evaluation model to support these kind of BI software could be an interesting topic for further studies.

\section{References}

Arik, J. (2005). What is Competitive Intelligence? Retrieved 2008-04-13 from http://www.aurorawdc.com.

Brynjolfsson, E., \& Yang, S. (1996). Information technology and productivity: A review of literature. Advances in Computers, 43, 170214.

Eckerson, W., White, C. (2003). Evaluating ETL and Data Integration Platform. Seattle, WA: The DW Institute.

Cognos (2008). Industry Analyst review. Retrieved 2008-04-14, from www.cognos.com.

Dan, S. (2004) Exploring Text with Qualitative Data Analysis. Retrieved 2008-05 27, from www.dmreview.com

Davenport, T. H., Harris, J. G. (2007). Competing on Analytics: The New Science of Winning Boston, MA: Harvard Business School Publishing.

Duggan, E. W. (2006). Measuring Information Systems Delivery Quality. Hershey, PA, USA: Idea Group Publishing,

Dutka, A. (2000). Competitive Intelligence for the Competitive Edge. Lincolnwood, IL, Contemporary Publishing Company.

Ericsson, R. (2004). Building Business Intelligence Applications with.net, Herndon, VA: Charles River Media.

Erikkson, I., McFadden, F. (1993). Quality function deployment: A tool to improve software quality. Information and Software Technology, 35(9), 491-498.

Fenton \& Pfleeger (1997). Software Metrics: A rigorous and Practical Approach, PWS Publishing Company.

Fuld \& Company intelligence report, 2006-2007, available at www.fuld.com

Gartner (2007). Business Intelligence Market Will Grow 10 Percent in EMEA in 2007. Retrieved 2008-04-15, from http://www.gartner.com/it/page.jsp?id=500 
Garvin, D. (1984). What does product quality really mean? Sloan Management Review, 24.

Gibbs, W. W. (1994). Software's chronic crisis. Scientific American, 271(3), 86-95.

Gilad, B. (1998). What is intelligence analysis? Part II. Competitive Intelligence Magazine, 1(3), 29-31.

Gilad, B \& Gilad, T. (1985). A systems approach to business intelligence, Business Horizons, 28(5): 65-70

Herring, J. P. (1993). Institutionalizing Our Profession. Competitive Intelligence Review, Vol. 4 (2-3), 86-88.

Keith G. (2006). The Forrester Wave ${ }^{\mathrm{TM}}$ : BI Reporting and Analysis Platforms, Q1.

Michael C. O'Guin, Ogilvie, T. (2001). The Science, Not Art, of Business Intelligence. Competitive Intelligence Review, Volume 12, Issue 4 (p 15-24).

Miller, S. H. (2001) CI: Now More than Ever Competitive Intelligence Review, Volume 12, Issue 4 ( p 1).

Palvia, P., and Chen, L. (2001) Proceedings of the Second Annual Global Information Technology Management World Conference

Bryant, P. (2001). CI is NOT Espionage! SCIP 2000-2001 Competitive Intelligence Review, Volume 11, Issue 3 (p 1-2).

Prescott, John (2001). Proven Strategies in Competitive Intelligence: Lessons from the Trenches. New York, NY: John Wiley \& Sons, p. 2.

Riemenschenider, B. C., Hardgrave, F. D. (2002). Exlaining Software Developer acceptance of methodologies. IEEE transactions on Software Engineering, 28, 12, pp. 1135-1145.

Soe-Tsyr Yuan and Ming-Zeng Huang (2001). A Study on Time Series Pattern Extraction and Processing for Competitive Intelligence Support, Expert Systems with Applications, Vol. 21(1), P. 37-51.

Solberg Søilen, Klaus (2005). Introduction to Private and Public Intelligence. Studentlitteratur: Lund

Thierauf, Robert J (2001); Effective Business Intelligence Systems Westport, CT, USA: Greenwood Publishing Group, Incorporated

Turban, Jay Aronson, Ting-Peng Liang and Ramesh Sharda (2007); Decision Support and Business Intelligence Systems, Pearson Education.

Van Grembergen, Wim (2001). Information Technology Evaluation Methods and Management. Hershey, PA: Idea Group Publishing, p 6.

Vriens, Dirk Jaap (2003). Information and Communications Technology for Competitive Intelligence. Hershey, PA: Idea Group Inc., p 2.
Watson, H. J. (2005). Sorting out what's New in Decision Support. Business Intelligence Journal. 